\title{
Electrical and thermal characteristics of MWCNTs modified carbon fiber/epoxy composite films
}

\author{
Aseel A. KAREeM*, Hussein Kh. Rasheed \\ Department of Physics, College of Science, University of Baghdad, Baghdad, Iraq
}

\begin{abstract}
To enhance interfacial bonding between carbon fibers and epoxy matrix, the carbon fibers have been modified with multiwall carbon nanotubes (MWCNTs) using the dip- coating technique. FT-IR spectrum of the MWCNTs shows a peak at $1640 \mathrm{~cm}^{-1}$ corresponding to the stretching mode of the $\mathrm{C}=\mathrm{C}$ double bond which forms the framework of the carbon nanotube sidewall. The broad peak at $3430 \mathrm{~cm}^{-1}$ is due to $\mathrm{O}-\mathrm{H}$ stretching vibration of hydroxyl groups and the peak at $1712 \mathrm{~cm}^{-1}$ corresponds to the carboxylic $(\mathrm{C}=\mathrm{O})$ group attached to the carbon fiber. The peaks at $2927 \mathrm{~cm}^{-1}$ and $2862 \mathrm{~cm}^{-1}$ are assigned to $\mathrm{C}-\mathrm{H}$ stretching vibration of epoxy produced at the defect sites of acid-oxidized carbon fiber surface. SEM image shows a better interface bonding between the fiber and the matrix of modified composites (MWCNTs-CF/Ep) than those of unmodified composite. The loss factor curve of CF-MWCNTs/Ep composites is the narrowest compared with neat epoxy and CF/Ep composites which evinces that the length distribution range of molecular chain segments in the matrix is the narrowest. From the dependence of the AC conductivity on temperature, we can see that $\sigma_{\mathrm{AC}}$ increases when temperature increases. The increase in electrical conductivity of the composites may be a result of the increased chain ordering due to annealing effect. The use of MWCNTs to modify the surface of carbon fiber resulted in a large amount of junctions among MWCNT causing an increase in the electrical and thermal conductivity by forming conducting paths in the matrix. The MWCNTs-CF/Ep composite shows better thermal stability than unmodified composites. The strong interaction between CF and MWCNTs can retard diffusion of small molecules from the resin matrix at high temperature and hence, result in the improved thermal stability of the modified $\mathrm{CF} / \mathrm{Ep}$ composite.
\end{abstract}

Keywords: surface modification; MWCNTs; epoxy/CF composites, thermal properties, electrical properties

\section{Introduction}

Technology trends toward low weight, highspeed electronic and optoelectronic applications and lower power dissipation, lead to an improvement in electronic systems [1-3]. The development of carbon fiber (CF) reinforced polymers (CFRPs) composite materials with specific types of enhanced functionality is required for applications in engineering, and particularly in the aerospace industry [4]. Carbon fiber reinforced polymers (CFRPs) have a highly anisotropic electrical and thermal resistivity, which limits their use in electrical and thermal applications [5]. The most critical issue of carbon fiber/epoxy (Ep) composites is compatibility between the CF and epoxy matrix which ultimately controls the interface between the $\mathrm{CF}$ and the polymer matrix as well as electrical and thermal dissipation [6, 7]. Multiwall car-

*E-mail: aseelalobaedY@yahoo.com bon nanotubes (MWCNTs) demonstrated their potential for enhancement of mechanical, thermal and electrical properties of CFRPs [8]. For modified CFRPs, two main approaches are possible for incorporating MWCNTs into the CFRP: (i) MWCNTs deposition on the fibers and (ii) MWCNTs dispersion in the matrix. Different techniques used to deposit MWCNTs on fibers, such as dipping, chemical vapor deposition (CVD), electrophoresis deposition or agglomeration of MWCNTs by sizing agents gave a significant improvement in the electrical and thermal properties [9]. In this contribution, dip coating technique was used for deposition of MWCNTs to create preferential conductive pathways within a nanocomposite and a multiscale composite in order to reduce their resistivity. With increasing cost of fuel, energy efficiency has become a major requirement for new aircraft designs, which has led to significant efforts for reducing their weight $[10,11]$. 
Regarding the modification of carbon fibers, Zhang et al. [12] modified carbon fiber/epoxy composites by introducing graphene oxide (GO) sheets dispersed in the fiber sizing onto the surface of individual carbon fibers. The surface topography of the modified carbon fibers and the distribution of GO sheets in the interfacial region of the carbon fibers were detected by scanning electron microscopy (SEM). Pozegic et al. [13] applied a coating to the surface of the carbon fibers to assist handling, improve the interfacial adhesion between the fiber and polymer matrix and allow this matrix to wet out the carbon fibers. A CNT modifiedCFRP showed $300 \%, 450 \%$ and $230 \%$ improvement in the electrical conductivity on the surface, through-thickness and in volume, respectively. Kim et al. [14] studied the effect of an aluminum nitride (AlN) ceramic coating on the thermal conductivity of carbon fiber-reinforced composites. Copper catalysts pre-doping enhanced the interfacial bonding of the AlN with the carbon fiber surfaces. Scanning electron microscopy (SEM); transmission electron microscopy (TEM); and X-ray diffraction (XRD) were used to analyze the carbon fiber surfaces and structures.

Awan et al. [15] coated carbon fibers with carbon nanotubes using two diverse coating techniques, i.e. dip coating and spray process, while the factors affecting the coating techniques were investigated. Microscopic observation under optical microscope confirmed the void-free impregnation of the fibers with epoxy along with the presence of nanotubes on the fibers. In this research work, the deposition of multiwall carbon nanotubes (MWCNTs) on carbon fibers has been achieved through a dip coating. After deposition, the composition and microstructure of modified $\mathrm{CF} / \mathrm{Ep}$ composites were investigated using FT-IR. Finally, the prepared composites were characterized for microstructural, thermal and electrical properties.

\section{Experimental}

Epoxy (OP105) supplied by (DCP, Amman, Jordan) was used as a polymer matrix. The epoxy resin consisted of two parts; part A: diglycidyl ether of bisphenol A, and part B: cycloaliphatic amine hardener in a stoichiometric ratio of $\mathrm{A}: \mathrm{B}=1: 3$. A bidirectional Toray's Torayca T700S-12 K Pan-based carbon fiber was used as a reinforcement material in the composites, which are commercially available from Zoltek Corporation, USA. To prepare the MWCNTs we have initially added $40 \mathrm{~mL}$ methyl-1-pyrrolidinone (NMP) to the appropriate amount of commercial MWCNTs obtained from Nanocyl S.A. (Belgium). The diameter of the used MWCNTs was $30 \mathrm{~nm}$ to $60 \mathrm{~nm}$, the length was $1.5 \mu \mathrm{m}$ to $400 \mu \mathrm{m}$ and purity $<90 \%$. The obtained solution was placed in a flask and stirred vigorously under ultrasonication for $12 \mathrm{~h}$ at room temperature to obtain a homogeneous suspension. Dip coating technique was used to deposit MWCNTs on carbon fibers. The sheets of carbon fabric of similar size were dipped separately in glass containers containing MWCNT suspension for $12 \mathrm{~h}$. After coating, the fabric was dried in an oven at $50{ }^{\circ} \mathrm{C}$ for $30 \mathrm{~min}$, and a simple hand-layup technique was used to prepare the composite as shown if Fig. 1.

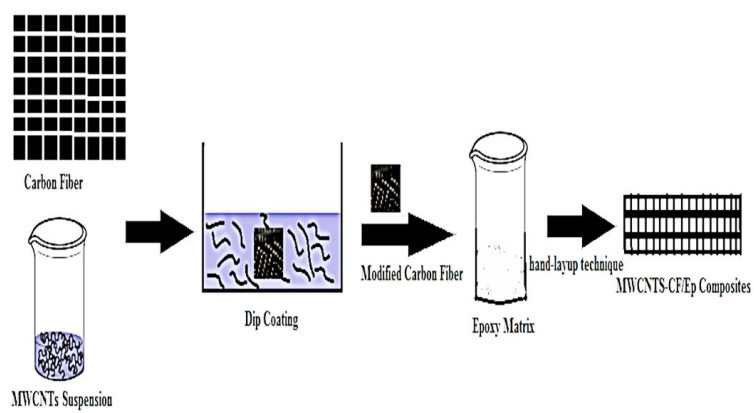

Fig. 1. Schematic diagram of preparation of MWCNTS-CF/Ep composites.

After obtaining the specimens of epoxycarbon fiber composite materials which were prepared in the form of plates with dimensions $(150 \mathrm{~mm} \times 150 \mathrm{~mm} \times 500 \mu \mathrm{m})$, they were cut and machined to obtain the specimen for thermal and electrical test. The IR absorption spectra were recorded by double beam Fourier transform infrared spectroscopy using FT-IR Shimadzu spectrophotometer model 8300, Japan, with potassium bromide source 
in the range of wave number $4000 \mathrm{~cm}^{-1}$ to $500 \mathrm{~cm}^{-1}$ with the resolution $0.5 \mathrm{~cm}^{-1}$. Microstructural properties were evaluated by a scanning electron microscope Hitachi, FE-SEM (S-4200) at an accelerating voltage of $10 \mathrm{kV}$ The sample surfaces were coated with gold to improve the conductivity. Dielectric parameters were measured by using the LCR meter model (HP-4275) at a fixed frequency of $100 \mathrm{kHz}$ and temperature range of $290 \mathrm{~K}$ to $375 \mathrm{~K}$. The thermal conductivity coefficient was measured by using a Lee's disk method. The samples used for thermal and electrical tests were cut to the same diameter as the copper plates $(40 \mathrm{~mm})$ and to a thickness of approximately $500 \mu \mathrm{m}$.

\section{Results and discussion}

Fig. 2 shows the FT-IR spectra of MWCNTs, $\mathrm{CF} / \mathrm{EP}$ composites and MWCNTs-CF/Ep composites, respectively. FT-IR spectrum of MWCNTs shows a peak at $1640 \mathrm{~cm}^{-1}$ corresponding to the stretching mode of the $\mathrm{C}=\mathrm{C}$ double bond which forms the framework of the carbon nanotube sidewall [16]. It does not show any other significant peaks. In case of CF/Ep composites, the broad peak at $3430 \mathrm{~cm}^{-1}$ is due to $\mathrm{O}-\mathrm{H}$ stretching vibrations of hydroxyl groups and the peak at $1712 \mathrm{~cm}^{-1}$ corresponds to the carboxylic $\mathrm{C}=\mathrm{O}$ group attached to carbon fiber. These two peaks are an indication of acid functionalization. The peaks at $2927 \mathrm{~cm}^{-1}$ and $2862 \mathrm{~cm}^{-1}$ are assigned to $\mathrm{C}-\mathrm{H}$ stretching vibrations of epoxy produced at the defect sites of acidoxidized carbon fiber surface [17].

The FT-IR spectrum of MWCNTs-CF/Ep composite confirms the formation of hydroxide groups on the MWCNTs surface. The peaks at $1267 \mathrm{~cm}^{-1}$ and $1370 \mathrm{~cm}^{-1}$ are ascribed to $\mathrm{C}-\mathrm{N}$ stretching of hydroxide groups, while the peak at $3420 \mathrm{~cm}^{-1}$ can be assigned to the $\mathrm{N}-\mathrm{H}$ stretching vibrations. The peaks at $1610 \mathrm{~cm}^{-1}$ and $1245 \mathrm{~cm}^{-1}$ correspond to the $\mathrm{N}-\mathrm{H}$ bending and $\mathrm{C}-\mathrm{N}$ stretches of amine, respectively [18].

The magnified image of the circular region in Fig. 3a, illustrates the dispersion state of the MWCNTs in the matrix-rich inter-fiber region

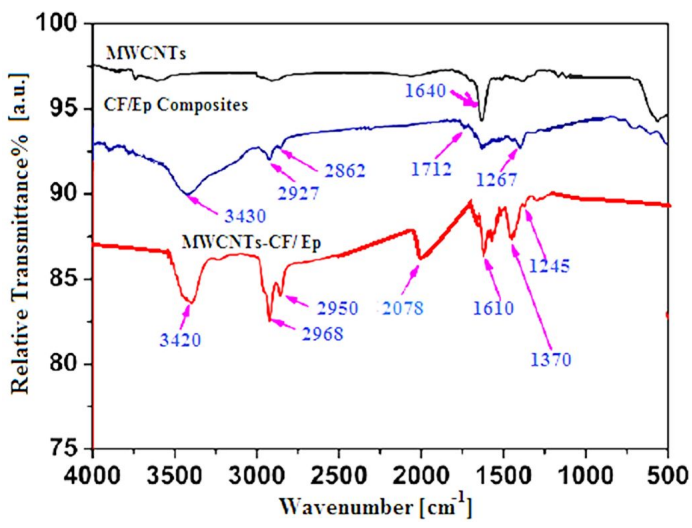

Fig. 2. Representative FT-IR spectra of MWCNTs, $\mathrm{CF} / \mathrm{Ep}$ composite and MWCNTs-CF/Ep composite.
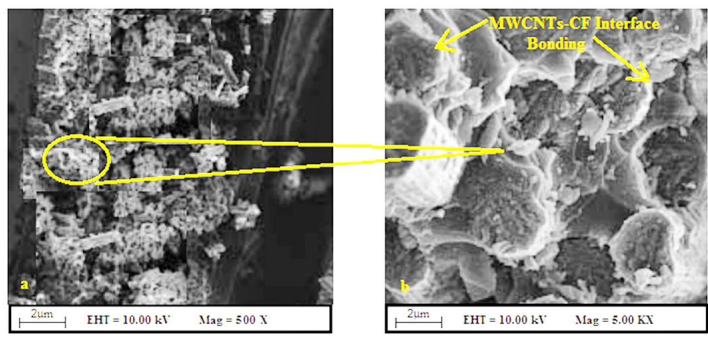

Fig. 3. SEM image of the cross-section region of (a) MWCNTs-CF/Ep composite, and (b) the magnified image of the circular region marked in (a).

of the MWCNTs-CF/Ep composite. The crosssection regions of the MWCNTs-CF/Ep composites (Fig. 3a and Fig. 3b) show that the addition of MWCNTs improved the interface interaction between the fiber and the matrix. This is due to the modification of carbon fibers by MWCNTs. The MWCNTs are expected to act as coupling enhancing agents for the interphase between the fiber and the matrix, thus, they interact both with the epoxy matrix and the CF. It results in better interfacial bonding between the fiber and the matrix [19].

Dielectric parameters, such as capacitance (C) and the dissipation factor $(\tan \delta)$, were measured by using LCR meter model (HP-4275). The dielectric constants $\left(\epsilon_{\mathrm{r}}\right)$ were calculated by the following equation:

$$
C=\varepsilon_{r} \varepsilon_{0} \frac{A}{d}
$$


where $\epsilon_{0}$ is vacuum permittivity and equals $8.85 \times 10^{-12} \mathrm{~F} / \mathrm{m}$. A is the electrode area $\left[\mathrm{cm}^{2}\right]$ and $\mathrm{d}$ is the thickness of the specimen $[\mathrm{cm}]$. AC conductivity $\left(\sigma_{\mathrm{AC}}\right)$ was calculated from the relation:

$$
\sigma_{A C}=\varepsilon_{o} w \varepsilon_{r} \tan \delta
$$

where $\tan \delta$ is the dielectric dissipation factor and $\omega$ the angular frequency. From Fig. 4 we can see that the loss factor curve of CF-MWCNTs/Ep composites shows the highest $\tan \delta$ value compared with neat epoxy and CF/Ep composites. This is due to enhanced interfacial interaction when the carbon fiber is modified with MWCNTs which leads to reduction of the mobility of polymer chains in the epoxy matrix [20]. The narrowest curve of CFMWCNTs/Ep composites evinces that the length distribution range of molecular chain segments in the matrix is the narrowest. It may be due to the fact that carboxylic acid groups loaded on the MWCNTs and carbon fiber surfaces reacted with the epoxy groups of resin which decreased the length of molecular chain segments [21].

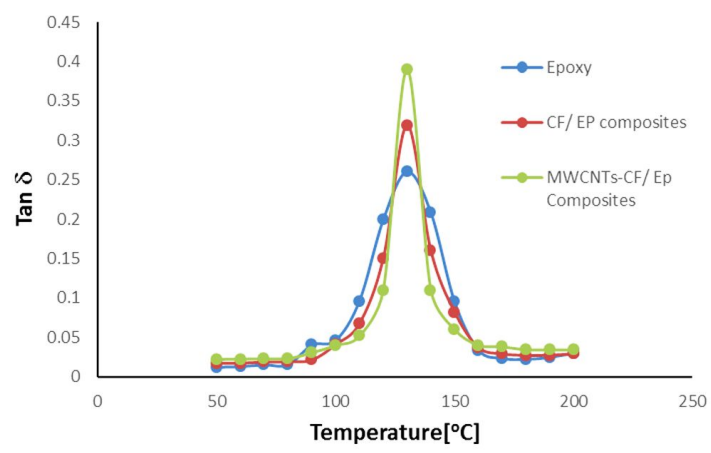

Fig. 4. Loss factor $(\tan \delta)$ as a function of temperature for epoxy, CF/Ep composite and MWCNTs$\mathrm{CF} / \mathrm{Ep}$ composite.

Fig. 5 shows the dependence of AC conductivity on temperature for epoxy, $\mathrm{CF} / \mathrm{Ep}$ composites and MWCNTs-CF/Ep composites. We can see that the $\sigma_{\mathrm{AC}}$ increases when temperature increases. The increase in electrical conductivity of the composites may result from the enhanced chain arrangement by annealing. Similar result has been reported in [22]. The use of MWCNTs to modify the surface of carbon fiber pressed a large amount of junctions among MWCNT resulting in an increase in the electrical conductivity by forming conducting path in the matrix [23].

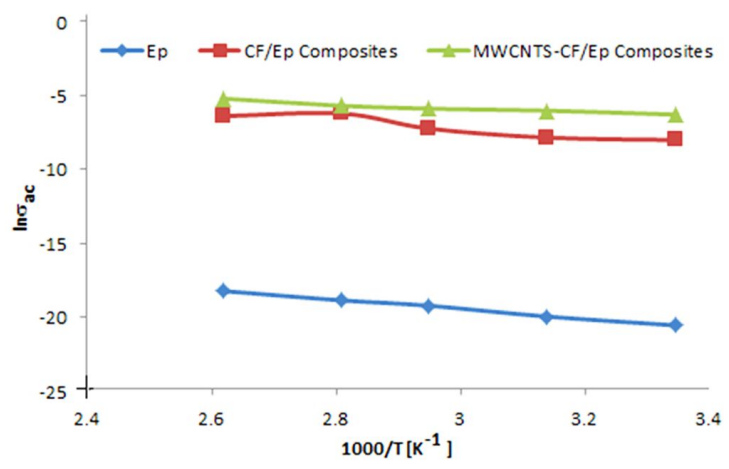

Fig. 5. Variation of $\ln \sigma_{\mathrm{AC}}$ with $1000 / \mathrm{T}$ for epoxy, $\mathrm{CF} / \mathrm{Ep}$ composite and MWCNTs-CF/Ep composite.

The thermal conductivity coefficient was obtained from the following Lee's disc experimental equations:

$$
\begin{gathered}
K \frac{T_{B}-T_{A}}{d_{S}}=e\left[T_{A}+\frac{2}{r}\left(d_{A}+\frac{d_{S}}{4}\right) T_{A}+\frac{1}{2 r} d_{S} T_{B}\right] \\
e=V I\left(a_{A} T_{A}+a_{S} \frac{T_{A}+T_{B}}{2}+a_{B} T_{B}+a_{C} T_{C}\right)
\end{gathered}
$$

where $\mathrm{K}$ is the thermal conductivity coefficient, e is the amount of thermal energy passing through a unit area per second of the disc material, $\mathrm{d}_{\mathrm{S}}$ is the thickness of the sample [mm], $\mathrm{T}$ is the temperature of the disk, $\mathrm{a}_{\mathrm{A}}, \mathrm{a}_{\mathrm{B}}, \mathrm{a}_{\mathrm{C}}$ are the areas of the disks $\mathrm{A}, \mathrm{B}, \mathrm{C}$ and $\mathrm{T}_{A}$, and $\mathrm{T}_{\mathrm{B}}, \mathrm{T}_{\mathrm{C}}$ are the temperatures of the disks $\mathrm{A}, \mathrm{B}, \mathrm{C}$, respectively. $\mathrm{V}$ is the potential difference across the heater and I is the current which flows through it.

From Fig. 6 we can see that the thermal conductivity increases when the MWCNTs modified the surface of carbon fibers. This is due to the fact that the use of MWCNTs provided large surface area and extended the shape of MWCNT which reduced crystallization of the matrix [24]. The large amount of junctions among MWCNT caused an increase in the thermal conductivity by forming conducting path along the carbon fiber epoxy matrix interface [25]. 
Table 1. Thermal analysis data of MWCNTs, CF/Ep composite and MWCNTs-CF/Ep composite.

\begin{tabular}{lllll}
\hline & $\mathrm{T}_{\mathrm{g}}\left[{ }^{\circ} \mathrm{C}\right]$ & $\mathrm{T}_{5}\left[{ }^{\circ} \mathrm{C}\right]$ & $\mathrm{T}_{10}\left[{ }^{\circ} \mathrm{C}\right]$ & $\mathrm{T}_{\max }\left[{ }^{\circ} \mathrm{C}\right]$ \\
\hline \hline MWCNTs & 62.8 & 310.3 & 322.1 & 478.8 \\
CF/Ep Composites & 75.4 & 297.8 & 338.9 & 510.4 \\
MWCNTs-CF/Ep & 82.3 & 334.4 & 352.5 & 525.5 \\
Composites & & &
\end{tabular}

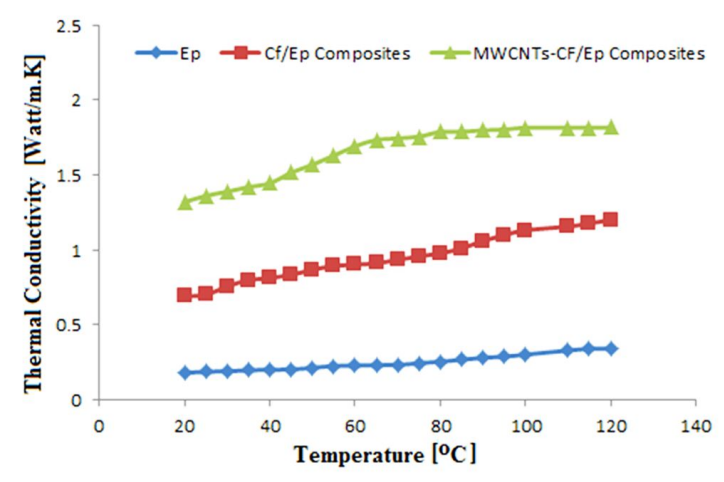

Fig. 6. Variation of thermal conductivity for epoxy, $\mathrm{CF} / \mathrm{Ep}$ composite and MWCNTs-CF/Ep composite.

Thermal stability of MWCNTs, CF/Ep composites and MWCNTs-CF/Ep composites was examined by TGA as shown in Fig. 7 and the results are listed in Table 1 . As shown in Table 1 , the $\mathrm{T}_{\mathrm{g}}$ of the MWCNTs-CF/Ep composite $\left(82.3{ }^{\circ} \mathrm{C}\right)$ is higher than that of the $\mathrm{CF} / \mathrm{Ep}$ composite $\left(75.4{ }^{\circ} \mathrm{C}\right)$. This increase in $\mathrm{T}_{g}$ might be due to silane molecules covalently bonded with MWCNTs, as silane-functionalization introduced a higher degree of crosslinks in the composite than in unmodified CF/Ep composites, which restricted the movement of molecules and thus resulted in higher $\mathrm{T}_{\mathrm{g}}[26,27]$.

From Fig. 7 and Table 1, the initial decomposition temperature for $5 \%$ weight loss $\left(\mathrm{T}_{5}\right)$, the decomposition temperature at $10 \%$ weight loss $\left(\mathrm{T}_{10}\right)$, and maximum decomposition temperature $\left(\mathrm{T}_{\max }\right)$ of the composite were measured. It was observed that the decomposition temperatures $\left(\mathrm{T}_{5}\right),\left(\mathrm{T}_{10}\right)$ and $\left(\mathrm{T}_{\max }\right)$ of the MWCNTs-CF/Ep composite increased by about $36{ }^{\circ} \mathrm{C}, 23.4{ }^{\circ} \mathrm{C}$ and $15^{\circ} \mathrm{C}$, respectively, as the surfaces of carbon fibers were modified by MWCNTs. The MWCNTs modified with carbon fibers improved the decomposition temperature of the composite. This clearly indicates that the MWCNTs-CF/Ep composite shows better thermal stability than the unmodified composites. The strong interaction between CF and MWCNTs can retard the diffusion of small molecules from the resin matrix at high temperature, hence, result in the improved thermal stability of the modified CF/Ep composite [28].

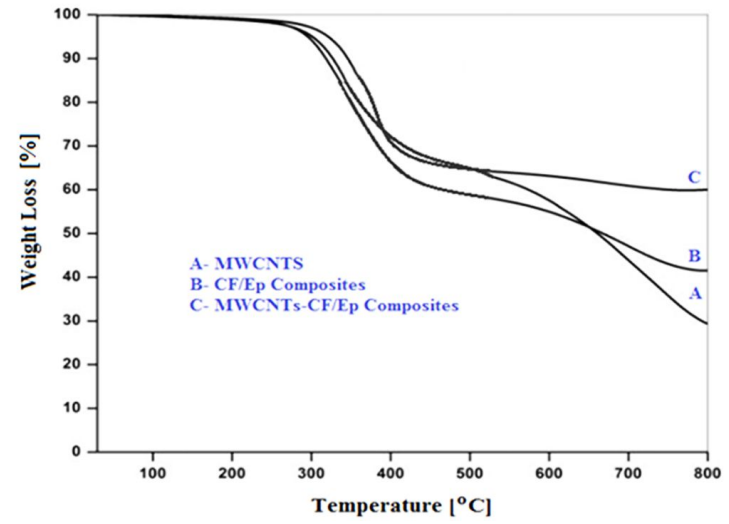

Fig. 7. TGA curves of MWCNTs, CF/Ep composite and MWCNTs-CF/Ep composite.

\section{Conclusions}

In this research, we investigated the effectiveness of using MWCNTs in polymer matrix composites in order to enhance interfacial bonding between $\mathrm{CF}$ and Ep matrix and reduce electrical and thermal dissipation. The results show that the modification of the surface of carbon fibers by applying MWCNTs improves structural, electrical and thermal properties of prepared composites.

\section{References}

[1] Goleanu A., Dunand M., Guichon J., SchaNen J., Coulomb J., $4^{\text {th }}$ Annual IEEE Systems Conference, San Diego, USA, 2010. 
[2] Potter K., An Introduction to Composite Products, Chapman \& Hall, United Kingdom, 1997.

[3] Kelly A., Composite Materials, Elsevier Science Ltd., New York, 1994.

[4] Sharpe L. H., The Interfacial Interactions in Polymeric Composites, Kluwer Academic Publishers, Netherlands, 1993.

[5] Singh B., Balasubramanian M., J. Mater. Process. Technol., 209 (2009), 2104.

[6] Xu Z., Wu X., Sun Y., Jiao Y., Li J., Chen L., J. Appl. Polym. Sci., 108 (2008), 1887.

[7] Guigon M., Klinklin E., Compos., 25 (1994), 457.

[8] XU X., Lin S., Li M., Li W., Jia X., Cai Q., YANG X., IOP Conf. Series: Mater. Sci. Eng., 87 (2015), 012088.

[9] Godara A., Mezzo L., Luizi F., WArrier A., LoMOV S., VuURe A., Carbon, 47 (2009), 2914.

[10] Pötschke P., Bhattacharyya A., Janke A., Carbon, 42 (2004), 965.

[11] Przepiorski J. A., Morawski A., Chem. Mater, 15 (2003), 862.

[12] Zhang X., Fan X., Yan C., Li H., Zhu Y., Li X., YU L., ACS Appl. Mater. Interfaces, 4 (2012), 1543.

[13] Pozegic T. R., Anguita J. V., Hamerton I., K. Jayawardena, Chen J. S., Stolojan V., BalLOCChi V. P., Walsh R., Silva S. R., Sci. Rep., 6 (2016), 1.

[14] Kim H., Lee Y., Chung D. C., Kim B., Coatings, 7 (2017), 1.

[15] Awan F. S., Subhani T., Adv. Nano Res., 1(2018), 14.

[16] Garg P., Pratap B., Kumar G., Gupta T., Pandey I., Seth R. K., Tandon R. P., Bihari R., J. Polym. Res., 18 (2011), 1397.
[17] Zhao Z., Teng K., Li N., Li X., Xu Z., Chen L., NiU J., Fu H., ZhaO L., LiU Y., Compos. Struct., 2017, vol. 159, pp. $761-772$,

[18] Genedy M., Daghash Sh., Soliman E., Taha M., Fibers, 3 (2015), 13.

[19] Moaseri E., Karimi M., Maghrebi M., BaniADAM M., Inter. J. Solid Struct., 51 (2014), 774.

[20] Yu K., Wang M., Wu J., Qian K., Sun J., Lu X., Nanomater, 6 (2016), 1.

[21] SzymCZyK A., Roslaniec Z., Zenker M., García-Gutiérrez M. C., Hernández J. J., Rueda D. R., Nogales A., EzQuerra T. A., eXPRESS Polym. Let., 5 (2011), 977.

[22] Arguin M., Sirois F., Therriault D., Adv. Manuf.: Polym. Compos. Sci., 1 (2015), 16.

[23] Arguin M., Sirois F., Therriault D., $19^{\text {th }}$ Int. Conference on Composite Materials, Montreal, Canada, 2013.

[24] Ciecierska E., BoczKowska A., Kurzydlowski K., Rosca I., HoA S., J. Therm. Anal. Calorim., 111 (2011), 1019.

[25] Ali A., Ahmad S., Tarawneh M., Malaysian J. Anal. Sci., 20 (2016), 1084.

[26] Kim S., Kim J., Kim H., Rhee K., Kathi J., J. Macromol. Sci., Phys., 51 (2012), 358.

[27] LeE J., PARK S., Kim Y., Murakami R., Results Phys., 9 (2018), 1.

[28] Ekramul M., Tanjheel I., Mahesh H., JeELANI V., Procedia Eng., 105 (2015), 821.

Received 2018-12-27 Accepted 2019-04-23 